\title{
Resíduos dos polos cerâmicos paulistas: Problema territorial e alternativa para a produção de matrizes cimentícias
}

\section{Residues from ceramic centers in São Paulo: Territorial problem and alternative for the production of cement matrixes}

\author{
Marco Antonio Campos ${ }^{1 *}$, Luciano Passos ${ }^{2}$, André Munhoz de Argollo Ferrão ${ }^{2}$, Armando \\ Lopes Moreno Junior ${ }^{2}$
}

\begin{abstract}
RESUMO
A localização dos principais polos cerâmicos no estado de São Paulo é concentrada em um raio de $100 \mathrm{~km}$ da cidade de Campinas-SP, nestas condições questões de ordenamento territorial versam sobre a extração das matérias-primas, envio da produção e principalmente na gestão dos resíduos cerâmicos. Devido ao grande volume de resíduos tornam-se necessárias ações para seu reaproveitamento caso da incorporação em matrizes cimentícias na substituição do cimento Portland. Os resíduos de telhas cerâmicas e isoladores elétricos de porcelana, quando finamente moídos são chamados de fíler cerâmicos e possuem atividade pozolânica. Nessas condições foram produzidas argamassas com matrizes cimentícias com baixo teor de cimento Portland, estes com teor de $70 \%$ e $20 \%$ de fíler cerâmico e $10 \%$ de sílica ativa. As argamassas foram ensaiadas a resistência à compressão simples nas idades de 28, 180 e 365 dias. Os resultados permitem de início o reaproveitamento destes resíduos cerâmicos, como matriz pozolânica em substituição ao cimento Portland, resultando em benefícios econômicos e ambientais e equacionando o potencial problema de ordenamento territorial de toda a cadeia produtiva cerâmica.
\end{abstract}

Palavras-chave: Ordenamento territorial; Resíduo cerâmico; Fíler cerâmico; Material pozolânico; Reciclagem.

\section{ABSTRACT}

The location of the main ceramic poles in the state of São Paulo is concentrated within a radius of $100 \mathrm{~km}$ from the city of Campinas-SP, in these conditions issues of territorial ordering deal with the extraction of raw materials, production dispatch and mainly the management of ceramic residues. Due to the large volume of residues, actions for its reuse become necessary in case of incorporation in cementitious matrices in the replacement of Portland cement. The residues of ceramic roof tiles and electrical porcelain insulators, when finaly ground are called ceramic filler and have pozzolanic activity. Under these conditions, mortars were produced with cementitious matrices with low Portland cement content, these with $70 \%$ and $20 \%$ ceramic filler and $10 \%$ active silica content. The mortars were tested for resistance to simple compression at periods of 28, 180 and 365 days. The results allow, for the initial, the reuse of these ceramic residues, as a pozzolanic matrix to replace Portland cement, resulting in economic and environmental benefits and equating the potential problem of territorial planning of the entire ceramic production chain.

Keywords: TerritorialPlanning; Ceramic residue; Ceramic filler; Pozzolanic material; Recycling.

\footnotetext{
${ }^{1}$ Consultor em Engenharia Civil e em Materiais de Construção Alternativos.

*E-mail: engenheiromarcoantonio@ hotmail.com

${ }^{2}$ Faculdade de Engenharia Civil, Arquitetura e Urbanismo da Universidade Estadual de Campinas - FECFAU-UNICAMP
} 


\section{INTRODUÇÃO}

Todo material cerâmico ao ser finamente moído resulta em potencial atividade pozolânica, isto é, capacidade de endurecer e oferecer resistência mecânica, quando misturado com água. Os resíduos da cerâmica vermelha, em especial telhas e blocos, e da cerâmica branca, isoladores elétricos de porcelana são os materiais mais indicados para serem reutilizados na construção civil, como material de matriz cimentícia devido ao potencial de atividade pozolânica.

Sob rigorosos controles na produção com queima em elevadas temperaturas da cerâmica vermelha - chegando a $950{ }^{\circ} \mathrm{C}$ - e dos isoladores de porcelana em até $1.500{ }^{\circ} \mathrm{C}$, tendo em vista a similaridade de sua composição com a do cimento Portland, propõe-se o uso destes materiais na forma de fíler cerâmico na produção de matrizes cimentícias com baixo teor de cimento Portland, isto é, parte do cimento substituída pelos resíduos cerâmicos finamente moídos.

Soma-se a estes fatores a potencialidade de utilização destes resíduos cerâmicos comprovada em trabalhos realizados pelos mesmos autores deste artigo. Em Campos (2018) observa-se o excelente potencial para utilização dos isoladores elétricos de porcelana como agregado de concretos e argamassas e até mesmo com agregado miúdo na confecção de blocos de concreto.

Já os resíduos de cerâmica vermelha foram destacados no trabalho de Passos (2019), tanto como substituição de parte do agregado graúdo na produção de concreto, quanto para substituição de parte do cimento, com teores de até $20 \%$ de substituição.

Portanto, o objetivo deste trabalho é mapear os polos cerâmicos localizados no estado de São Paulo, em especial, aqueles localizados em um raio de até $100 \mathrm{~km}$ da cidade de Campinas-SP, identificando seus tipos de resíduos e propondo a reutilização como constituinte em matrizes cimentícias de baixo teor de cimento Portland.

Os resíduos de cerâmica vermelha, telhas, e cerâmica branca, isoladores de porcelana, chamados de fíler cerâmicos, foram finamente moídos e adicionados na matriz cimentícia de argamassas na proporção de $70 \%$ de cimento Portland, $10 \%$ de sílica ativa e $20 \%$ de fíler cerâmico.

A combinação de fíler foi de um traço com $20 \%$ de resíduos de cerâmica vermelha, um traço com $20 \%$ de resíduos de isoladores elétricos de porcelana, e um traço de mistura de $10 \%$ de cerâmica vermelha e $10 \%$ de isolador. 
Estas argamassas foram ensaiadas à resistência à compressão simples nas idades de 28, 180 e 365 dias, comparando estes resultados a uma argamassa de referência, isto é, com matriz cimentícia de $100 \%$ de cimento Portland, apresentando resultados condizentes com as normas vigentes e, passível de aplicação na construção civil, sendo, portanto, uma alternativa ambiental e economicamente viável frente ao cimento Portland.

\section{O SETOR CERÂMICO PAULISTA}

O estado de São Paulo concentra a maior produção nacional de cerâmica, com destaque para os polos de produção de telhas, placas de revestimento, tijolos e blocos, e isoladores de porcelana distribuídos por todo seu território. Na região de Campinas, em um raio de $100 \mathrm{~km}$ se concentra uma grande quantidade de polos cerâmicos (Figura 1).

Destacam-se o Polo de Socorro - cerâmica de porcelana, com a cidade de Pedreira concentrando $80 \%$ da produção nacional de isoladores elétricos de porcelana. Nos polos de Mogi Mirim e Rio Claro se concentram as indústrias de pisos cerâmicos, e o Polo de Itu com a produção de blocos e telhas resultando em sua maior produção cerâmica. Nesses polos existem também outros tipos de produtos como as cerâmicas de mesa e de decoração.

Figura 1 - Polos cerâmicos no estado de São Paulo.

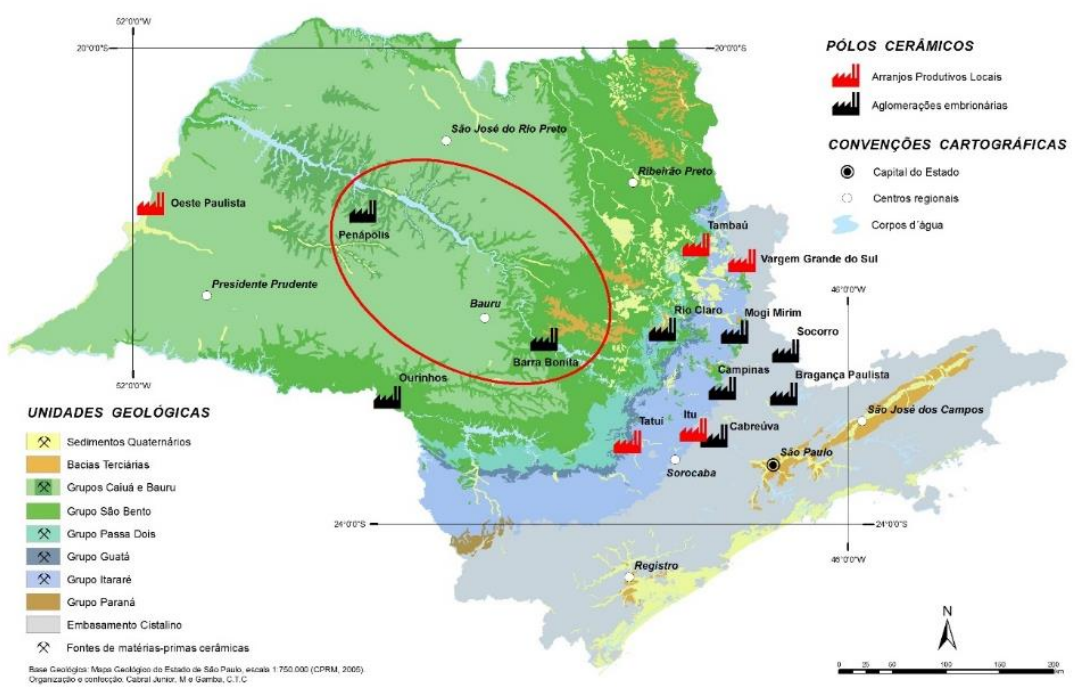

Fonte: São Paulo (2021).

Em todas estas regiões há indústrias cerâmicas produtoras de blocos cerâmicos, que nos últimos anos vêm ganhando mercado frente aos blocos de concreto, em 
decorrência do desenvolvimento das técnicas de produção com o aumento da resistência e o aprimoramento das técnicas de aplicação. Estes blocos cerâmicos possuem características estruturais e baixo peso, o que facilita a aplicação na obra e contribui para a diminuição do tempo de execução das alvenarias.

É necessário observar o ordenamento territorial para a localização das cerâmicas próximo às minas de extração de argila e dos polos consumidores, pois a viabilidade econômica das peças de menor custo depende do deslocamento máximo - que não deve ultrapassar $250 \mathrm{~km}$ de distância. É o caso de tijolos e blocos cerâmicos. Telhas e pisos possuem viabilidade para um deslocamento de até $500 \mathrm{~km}$, ao passo que para peças especiais o deslocamento não deve ultrapassar $750 \mathrm{~km}$ para serem viáveis economicamente (BUSTAMANTE; BRESSIANI, 2000).

Se os deslocamentos forem superiores aos relatados aqui, há correspondente aumento de despesas com transporte e as matérias-primas passam a ter um peso maior nos custos operacionais da indústria cerâmica. Entretanto, ações devem ser realizadas para que na inviabilidade da aplicação destas matérias-primas estas possam ser substituídas por resíduos da própria cadeia produtiva, com as indústrias cerâmicas agregando valor econômico e ambiental aos seus resíduos para que estes sejam descartados de forma correta, não comprometendo a natureza e, principalmente, sejam reutilizados em seu próprio processo fabril ou em outro setor industrial (LOPES; BRITO; MOURA, 2016).

Conforme apresentado pela Associação Brasileira de Cerâmica - ABCERAM, os dados estatísticos do Setor Cerâmico Brasileiro são incompletos com relação a informações de mercado, número de indústrias e colaboradores, faturamento e principalmente com respeito aos dados de produção. De fato, seria possível mensurar com maior precisão a produção destes polos cerâmicos, estimando o volume de resíduos gerado e potencializando sua aplicação.

A ABCERAM indica em seu site que a consulta dos dados do setor cerâmico deve ser realizada junto a outras associações de classes e sindicatos. Como exemplo: ASPACER - Associação Paulista das Cerâmicas de Revestimento; ANFACER Associação Nacional de Fabricantes de Cerâmica para Revestimento; ALAFAR Associacion Latinoamericana de Fabricantes de Refractarios; ANICER - Associação Nacional da Indústria Cerâmica; SINDILOUÇA - Sindicato da Indústria da Cerâmica de 
Louça de Pó de Pedra, da Porcelana e da Louça de Barro no Estado de São Paulo (ABCERAM, 2021).

Frente à dificuldade de encontrar dados consolidados do setor cerâmico, os autores buscaram informações junto a associações de classes e referências de outras pesquisas sobre o tema, a fim de se obterem parâmetros para embasar a possibilidade de aplicação destes resíduos em escala comercial. Os setores da cerâmica branca, em relação aos isoladores elétricos de porcelana tinham no ano de 1998 uma produção da ordem de 24.000 toneladas anuais (BUSTAMANTE; BRESSIANI, 2000), que é estimada atualmente em cerca de 30.000 toneladas/ano (CAMPOS, 2018; IPT, 2018). Este é um setor que tem sua expansão dependente dos investimentos dos setores públicos para sua expansão.

Entretanto é possível um aumento considerável da produção, pois o parque fabril brasileiro deste tipo de cerâmica tem capacidade instalada de 50.000 ton/ano. (BUSTAMANTE; BRESSIANI, 2000). Outro diferencial deste setor, segundo Campos; Paulon; Dalfré Filho (2013), é que 80\% da produção nacional está concentrada no Polo Cerâmico de Socorro, mais precisamente na cidade de Pedreira, interior de São Paulo, o que poderia ser uma problema em relação a concentração do volume dos resíduos gerados, porém, poderia ser também uma solução para as indústrias cerâmicas, se houvesse uma colaboração técnica entre elas para o desenvolvimento de novos produtos, compartilhamento de custos e lucros com o reaproveitamento dos resíduos.

Bustamante; Bressiani (2000) classificam as cerâmicas vermelhas em dois setores conforme os tipos de produtos produzidos. O Setor de Cerâmica Vermelha Estrutural engloba os seguintes produtos: tijolos furados, tijolos maciços, tavelas ou lajes, blocos de vedação e estruturais, telhas, manilhas e pisos rústicos, com uma produção estimada no ano de 2000 de 60.000 .000 toneladas anuais. Com a expansão imobiliária da última década no Brasil a produção paulista, no ano de 2016, foi superior a 12.000 .000 toneladas (IPT, 2018).

Outro setor da cerâmica vermelha formado pelas peças de revestimentos como azulejos, pisos e revestimentos de paredes externas, produziu no ano de 1998 um total de 400.700.000 $\mathrm{m}^{2}$ (BUSTAMANTE; BRESSIANI, 2000). Atualizando estes dados conforme o levantamento da ANFACER - Associação Nacional dos Fabricantes de Cerâmica para Revestimentos, Louças Sanitárias e Congêneres, a produção nacional no ano de 2020 foi de $840.000 .000 \mathrm{~m}^{2}$. 
Deste total de revestimentos cerâmicos mensurados pela ANFACER no ano de 2020, os pisos corresponderam por 474 milhões de $\mathrm{m}^{2}$, azulejos 179 milhões de $\mathrm{m}^{2}$, revestimento de fachada com 18 milhões de $\mathrm{m}^{2}$ e porcelanato com 168 milhões de $\mathrm{m}^{2}$.

Analisando apenas aos dados de mercado do Polo Cerâmico de Rio Claro a ASPACER - Associação Paulista das Cerâmicas de Revestimento ilustra está região como o maior polo produtor de revestimento das Américas com uma produção estimada de $495.250 .000 \mathrm{~m}^{2}$, correspondendo a $92 \%$ de toda a produção paulista e com suas indústrias localizadas em apenas sete municípios: Santa Gertrudes, Rio Claro, Cordeirópolis, Limeira, Piracicaba, Ipeúna e Iracemápolis (ASPACER, 2021).

A indústria cerâmica, em especial os setores de cerâmica vermelha, concentra a sua produção para o atendimento do mercado interno, com as indústrias locais suportando o aumento das demandas da última década.

Em relação a participação de produtos importados, o setor de cerâmica estrutural, blocos, telhas e tijolos é atendido basicamente pelas empresas nacionais, ao passo que o setor de revestimento tem um nicho de mercado para alguns tipos específicos de cerâmica importada, além da recente instalação de algumas empresas multinacionais.

A exportação dos produtos de cerâmica vermelha não tem participação significativa na balança comercial brasileira, o setor de revestimento apresenta uma tímida taxa de exportação, que muitas vezes é atrelada ao valor do câmbio monetário. Entretanto, a cerâmica branca, isoladores elétricos de porcelana, tem grande parte de sua produção destinada ao mercado externo (PRADO; BRESSIANI, 2012).

Devido às características de produção, instalações industriais e valor agregado, o setor cerâmico apresenta um elevado índice de descarte decorrente do controle de qualidade de suas peças. Mesmo com a utilização de parte destes resíduos na moldagem de novas peças cerâmicas ainda se tem um grande volume que acaba por acumular nos pátios das indústrias e que não tem uma metodologia muito menos uma regulamentação normativa para seu correto descarte, reciclagem e/ou reutilização.

Estes grandes volumes de cerâmica descartados passam a ser um problema de ordenamento territorial, pois tem-se em determinada região a extração das matériasprimas, seguida da produção, que muitas vezes é realizada em indústrias com métodos de produção ultrapassados. Nestas condições o controle de qualidade impede que porcentagem relativa das peças produzidas cheguem aos consumidores (CAMPOS; PAULON; DALFRÉ FILHO, 2013). 
No caso dos isoladores elétricos de porcelana o problema de descarte das peças não ocorre apenas quando da não conformidade do controle de qualidade. Há também o descarte de peças substituídas devido a perda das funções das partes metálicas. Atualmente é crescente a substituição de isoladores de porcelana por isoladores poliméricos (RODRIGUES, 2010).

Entretanto, o corpo cerâmico possui uma vida útil muito superior a dos materiais metálicos. Devido a inviabilidade de substituição do metal, muitas vezes as distribuidoras de energia acabam por leiloar os isoladores substituídos, que são adquiridos por empresas de sucata elétrica apenas com a intenção de comercialização das partes metálicas, e acabam, em alguns casos, descartando na natureza o corpo cerâmico, como pode ser constatado na Figura 2.

Figura 2 - Descarte na natureza de isoladores elétricos de porcelana substituídos.
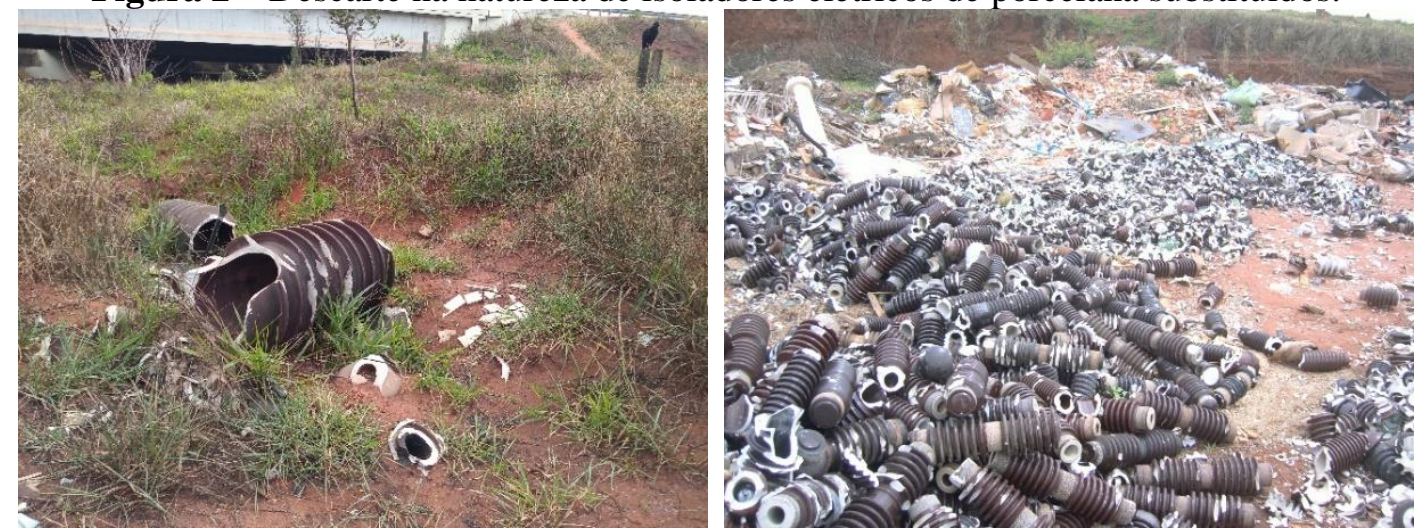

Fonte: Elaboração dos autores (2022).

Os resíduos de cerâmica vermelha, como recortes de peças de revestimento e recorte de telhas, também são descartados em meio a natureza, em especial em estradas rurais, mas como estes são mais frágeis que a porcelana, acabam por muitas vezes sendo triturados com a passagem de veículos e se misturam ao solo. Muitas vezes os proprietários das obras contratam caçambas para recolhimento destes resíduos, mas são descartados em locais indevidos por estas empresas, acarretando potenciais danos irreversíveis a natureza.

Compilando os dados de produção da indústria cerâmica paulista e atribuindo um descarte de apenas $2 \%$ do total produzido, que pode ser atribuído ao controle de qualidade fabril, tem-se considerável quantidade de resíduo cerâmico, que pode ser, na inicial, moído em granulometria ao cimento Portland e utilizado na matriz cimentícia. 
Apresenta-se na Tabela 1 um levantamento básico deste potencial de material cerâmico proveniente do descarte de $2 \%$ de toda a produção do estado de São Paulo e que potencialmente poderia ser reutilizado na forma de fíler em matrizes cimentícias. Destaca-se que o setor de revestimento cerâmico tem sua produção em metros quadrados o que dificulta mensurar a proporção destes resíduos em metro quadrado para toneladas. Por este motivo este resíduo de cerâmica vermelha não será objeto análise quanto a seu potencial de resíduo.

Tabela 1 - Produção cerâmica e potencialidade de material a ser reciclado.

\begin{tabular}{lccc}
\hline Produto Cerâmico & Produção * & Descarte / Resíduo & Material reciclado \\
\hline Isolador de porcelana & 30.000 ton/ano & $2 \%$ & 600 ton/ano \\
\hline Cerâmica vermelha & 12.000 .000 ton/ano & $2 \%$ & 240.000 ton/ano \\
\hline * Produção estimada para o ano de 2020. \\
\multicolumn{4}{c}{ Fonte: Elaboração dos autores (2022). }
\end{tabular}

Assim como o setor cerâmico é passível de dificuldade em mensurar a real produção, a produção anual brasileira da sílica ativa não tem dados compilados que permitem determinar a quantidade de produto disponibilizada.

\section{MATRIZES CIMENTÍCIAS COM BAIXO TEOR DE CIMENTO PORTLAND}

Formada por aglomerantes minerais, em especial o cimento Portland, as matrizes cimentícias podem receber agregados resultando em pastas, argamassas e concretos. Portanto, define-se matriz cimentícia como a parte aglomerante de uma argamassa, isto é, o material que em contato com água resulta em produtos hidratados que conferem resistência quando endurecidos. Tem-se, com isso, o cimento Portland como o material aglomerante mais empregado para atender estas condições.

Devido a esta versatilidade e grande utilização o cimento Portland foi o responsável pelos avanços tecnológicos da construção civil que permitiram a construção de edifícios cada vez mais altos, pavimentos mais resistentes e obras mais duráveis, por exemplo. Entretanto, não é apenas o uso do cimento que resulta nestes benefícios, pois vários fatores impactam diretamente em suas propriedades como o seu teor máximo, a relação água/cimento, condições de cura e local de aplicação. Somam-se a estes fatores, as características, propriedades, granulometria e tipos dos agregados utilizados nos concretos e argamassas. 
Em relação a quantidade de cimento em concretos e argamassas, é comum, principalmente em obras sem controle de qualidade, o aumento de seu teor para elevação da resistência. Mas este elevado teor de cimento pode desencadear alguns malefícios a estrutura, pois a hidratação do cimento é de natureza exotérmica, isto é, libera grande quantidade de calor o que pode comprometer grandes peças de concreto como barragens, blocos de fundação, paredes e pilares.

Com o calor há a dilatação térmica, aumento do volume, seguido do resfriamento e retração, podendo resultar em fissuras, pois o concreto e a argamassa apresentam baixa resistência à tração. Estas fissuras podem ser o caminho a preferencial a ser percorrido pela penetração de ar, água e agentes agressivos comprometendo toda a estrutura (REBMANN, 2011). Outro ponto negativo dos elevados teores de cimento refere-se a indústria cimenteira que é uma das maiores fontes poluidoras do mundo e contribui para os problemas ambientais que o planeta vem sofrendo nos últimos anos e que são atribuídos aos gases de efeito estufa.

Com esta preocupação, inúmeras pesquisas surgiram em relação à obtenção de matrizes cimentícias com baixo teor de cimento, isto é, diminuição da quantidade de cimento Portland obtendo os mesmos padrões de qualidade, trabalhabilidade, resistência e durabilidade. A maioria delas refere-se a utilização de sílica ativa ou outro material com elevada atividade pozolânica, como o metacaulim.

A busca por estes materiais alternativos ao cimento baseia-se em três aspectos principais: tecnológicos, pois as pozolanas tendem a aumentar a trabalhabilidade devido ao formato esférico de seus grãos, reduzir o consumo de água, melhorar as propriedades mecânicas e de durabilidade, pois tem-se um refinamento dos poros e dos cristais presentes na pasta de cimento hidratada; econômicos, diminuindo a quantidade de cimento, insumo de valor considerável no custo da obra, e; ecológicos, pois as pozolanas são constituídas de resíduos industriais que seriam descartados muitas vezes em aterros sanitários (CARMO; PORTELLA, 2008).

A sílica ativa é um material com propriedades pozolânicas proveniente do resíduo da produção de silício ou ligas de ferro-silício, com o $\mathrm{SiO}_{2}$, expelido na forma de fumaça, se condensando em finas partículas esféricas altamente reativas, acelerando a reação com o $\mathrm{Ca}(\mathrm{OH})_{2}$. Por possuir grãos muito finos a sílica ativa pode preencher o espaço entre os grãos de cimento, melhorando o empacotamento e consequentemente a resistência (NEVILLE; BROOKS, 2013). 
Com todos estes pontos a sílica ativa é um material altamente pozolânico, mas de difícil manuseio, pois aumenta a necessidade de água no concreto, que pode ser contornada com a adição de aditivos redutores de água. Entretanto, grandes obras de concreto tendem a ser as obras preferenciais para a utilização deste material, em especial devido ao rígido controle de qualidade nas etapas de dimensionamento e produção dos traços de concreto que estas obras exigem.

O teor de substituição do cimento Portland por sílica ativa é da ordem de $10 \%$ e os benefícios constatados por inúmeros autores foram de melhoria na trabalhabilidade da mistura, aumentos de resistências à compressão simples e à tração por compressão diametral. Quando aos ensaios de resistência à tração na flexão os valores obtidos foram próximos ao traço de referência (DAL MOLIN, 1995; CARMO; PORTELLA, 2008).

Outro material finamente moído utilizado em concretos é o fíler, que resulta em benefícios nas propriedades de trabalhabilidade, massa específica, permeabilidade, exsudação capilar e tendência à fissuração (MEHTA; MONTEIRO, 2008). Sua fonte pode ser de materiais de origem natural ou materiais processados inorgânicos. No Brasil o fíler pode ser utilizado na composição de cimentos Portland compostos, até o limite de 10\% (DAL MOLIN, 2005).

Assim como a sílica ativa o fíler também contribui para o aumento do teor de água no concreto, afetando negativamente a resistência do concreto ao intemperismo ou a proteção às armaduras. De natureza inerte o fíler não causa diminuição da resistência do concreto à longo prazo (NEVILLE; BROOKS, 2013). Apesar destes pontos negativos em relação a utilização de sílica ativa e fílers, seu uso vem crescendo no Brasil nos últimos anos, sendo uma importante ferramenta para reaproveitamento destes resíduos. E com o avanço das pesquisas todos estes fatores deletérios são contornados com estudo de traço, incorporação de aditivos e melhores práticas nos canteiros de obras.

O emprego de fíler cerâmico em argamassas de revestimento de cal é técnica difundida e utilizada por muitos séculos em Portugal, como atesta o trabalho de Matias et al. (2012), o qual ilustra a situação de que desde o Império Romano resíduos de cerâmica vermelha erma utilizados em granulometria fina, similar a da cal, como material pozolânico, e com grãos de maiores dimensões como agregado nestas argamassas de cal aérea.

Atualmente o processo de industrialização da cerâmica permite haver inúmeros tipos de materiais com potenciais atividades pozolânicas que poderiam ser finamente 
moídos e reaproveitados e não descartados na natureza. Nesta linha Matias et al. (2012) estudaram o comportamento de argamassas de cal aérea com três resíduos cerâmicos: tijolos, telhas e vasos, em substituição parcial do volume do agregado de $20 \%$ e $40 \%$, mas com a intenção de que estes resíduos atuarem mais como um material aglomerante do que agregado.

Em relação aos ensaios de resistência à compressão simples quanto maior o teor de cerâmica e maior a idade de ensaios mais elevadas foram as resistências obtidas, demonstrando que o resíduo cerâmico tem uma potencial atividade pozolânica (MATIAS et al., 2012).

Farias Filho et al. (2000) avaliaram a potencialidade do uso de resíduos de produção de tijolos cerâmicos queimados finamente moídos, como substitutos parciais do cimento Portland, em teores de 20 a 50\%, indicando que estes resíduos possuem uma elevada atividade pozolânica. Fator este que foi comprovado através da realização dos ensaios de atividade pozolânica e em relação a resistência à compressão simples.

A substituição do cimento Portland por resíduos de blocos cerâmicos para a confecção de concretos foi elaborada por Rocha (2008) com traços contendo $20 \%$ de resíduo cerâmico e esta mesma quantidade combinada com resíduo do corte de rocha. Os resultados, em relação aos ensaios de resistências à compressão simples, à tração por compressão diametral e à tração na flexão, indicam valores inferiores ao observados no concreto de referência, com 100\% de cimento, e justificado pelos autores em decorrência do aumento da relação água/cimento e da baixa atividade pozolânica do resíduo cerâmico nestes concretos alternativos.

Já no trabalho de Oliveira et al. (2012) verificou a resistência de argamassas contendo resíduos de telha e de tijolos em substituição ao cimento e em ambos os casos foi constatada a diminuição da resistência à compressão das argamassas com baixo teor de cimento quando comparada a traço de referência. Destaca-se que nesta pesquisa os teores de substituição de cimento foram de $10 \%$ a $40 \%$

Em Medeiros et al. (2016) a verificação da durabilidade das argamassas contendo fíler cerâmico ocorreu através dos ensaios de resistência à reação álcali-sílica e de resistência ao ataque por sulfato de sódio. Quando da utilização de agregados os autores não indicam a utilização dos resíduos cerâmicos e indicam que estes devam ser finamente moídos para se obter melhor empacotamento dos grãos com aumento de resistência mecânica e ao ataque por sulfatos. 
Apesar da verificação de inúmeras pesquisas comprovarem a potencialidade dos resíduos cerâmicos vermelhos como material pozolânico em matrizes cimentícias, outros trabalhos relatam diminuição nas propriedades analisadas em função do tamanho dos grãos, relação água/cimento e principalmente, é necessário que a fonte de resíduo também seja de qualidade, isto é, o material cerâmico deve ser constituído de uma argila de qualidade e principalmente deve ser queimada em temperaturas ideias, para que ao ser finamento moído resulte em um material pozolânico quando hidratado.

Se os trabalhos nacionais que versam sobre a utilização de fíler de cerâmica vermelha são poucos, quando comparados ao estudo destes resíduos em substituição aos agregados, aqueles que estudam a utilização de fíler de cerâmica branca, no caso as porcelanas, são ainda mais escassos. Entretanto, este grupo de autores vêm publicando alguns trabalhos com a temática da incorporação de isoladores elétricos de porcelana na matriz cimentícia.

No ano de 2016 Argollo Ferrão; Campos; Paulon produziram argamassas com a adição em massa do cimento Portland em teores de 5\%, 10\%, 25\%, 50\% e 70\%. Os resultados dos ensaios mecânicos de resistência à compressão simples, à compressão diametral e à tração na flexão indicam a utilização dos isoladores de porcelana em adição ao cimento. Os benefícios da incorporação da porcelana são confirmados através da formação dos compostos de hidratação da pasta de cimento observada nos ensaios de MEV.

A incorporação de porcelana ao cimento também foi objeto de estudo no trabalho de Campos; Argollo Ferrão (2018) onde foram produzidos blocos de concreto combinando cimento Portland, isolador de porcelana e areia de descarte de fundição, como um conjunto de materiais finos. Nestas condições, os blocos de concreto atenderam os requisitos da norma brasileira em vigor, indicando a utilização do resíduo de porcelana.

Em Campos et al. (2018) foi estudada a substituição por cimento por uma combinação de sílica ativa (10\%) com resíduo de cerâmica vermelha (20\%) e sílica com isolador de porcelana (20\%) obtendo os concretos com materiais alternativos resistência inferior ao traço de referência. Porém, nos traços de argamassa a que continha fíler de porcelana apresentou resistência superior a referência. Em todos os trabalhos deste grupo de pesquisadores os isoladores elétricos de porcelana foram fornecidos por uma cerâmica da cidade de Pedreira-SP, pertencente ao Polo Cerâmico de Socorro. 
No ano de 2013 o trabalho de Ferreira et al. 2013, estudou argamassas e pastas com substituição de até $40 \%$ do cimento Portland por isoladores elétricos de porcelana inservíveis de linhas de transmissão de uma distribuidora de energia da região de Campinas, interior de São Paulo. Ao analisar os resultados dos ensaios mecânicos como resistência à compressão simples, os autores indicam uma substituição de até $20 \%$ do cimento por isoladores de porcelana.

No trabalho de Beraldo; Shiroma; Ferreira (2014) foi estuda a adição de resíduos de isoladores de porcelana nos teores de $20 \%$ e $30 \%$ em matrizes cimentícias e com estes teres combinados com resíduos de Pinus. De início os autores recomendam a utilização da porcelana devido ao benefício ambiental e econômico.

Os autores atribuíram a diminuição da resistência à flexão estatísticas a identificação de pequenas fissuras, durante o processo de cura. Porém, indicam como traço ideal desta pesquisa com 30\% de porcelana e 19\% de partículas de Pinus (BERALDO; SHIROMA; FERREIRA, 2014).

A aplicação de um produto da construção civil com isoladores elétricos de porcelana em substituição ao cimento foi tema de estudo de Soares (2016) no qual foram ensaiadas argamassas colantes com estas características. Os resultados indicaram uma alteração no tempo de início e fïm de pega, porém, também foram observadas melhorias nas propriedades mecânicas, no qual um teor de $20 \%$ de isolador de porcelana é indicado na substituição do cimento.

Em Viera (2017) a produção de um traço de concreto com $8 \%$ de substituição do cimento Portland por isoladores de porcelana não obteve o desempenho esperado em relação ao aumento da resistência, que é atribuído em outras pesquisas à atividade pozolânica da cerâmica. Apesar desta constatação os valores dos ensaios de resistência mecânica foram similares ao traço de referência, comprovando em mais uma pesquisa a potencialidade de uso dos isoladores elétricos de porcelana em matrizes cimentícias.

Em todos os casos em que a matriz cimentícia continha isoladores de porcelana atuando como fíler cerâmicos, os resultados de resistência à compressão simples foram superiores aos traços, tanto de argamassa como concreto, de referência. Esta melhora na resistência é atribuída ao melhor processo de produção dos isoladores, com maior controle de qualidade das matérias-primas, que são queimadas a temperaturas mais elevadas que as cerâmicas vermelhas. 


\section{MATERIAL E MÉTODOS}

Identificados os resíduos cerâmicos existentes nos polos cerâmicos localizados próximos a cidade de Campinas, interior do estado de São Paulo, foram escolhidos dois tipos: cerâmica vermelha proveniente de telha cerâmica, do Polo de Itu, Figura 3 e cerâmica branca, do Polo de Socorro, tendo os isoladores elétricos de porcelana como fonte fornecedora, Figura 4. Todos estes materiais foram finamente moídos em granulometria similar ao cimento Portland e posteriormente analisados através da técnica de EDS (Espectroscopia por Dispersão de Elétrons) para a caracterização semiquantitativa de seus elementos químicos constituintes.

Figura 3 - Resíduo de cerâmica vermelha (a) moído em granulometria similar ao cimento Portland e seu respectivo EDS (b).

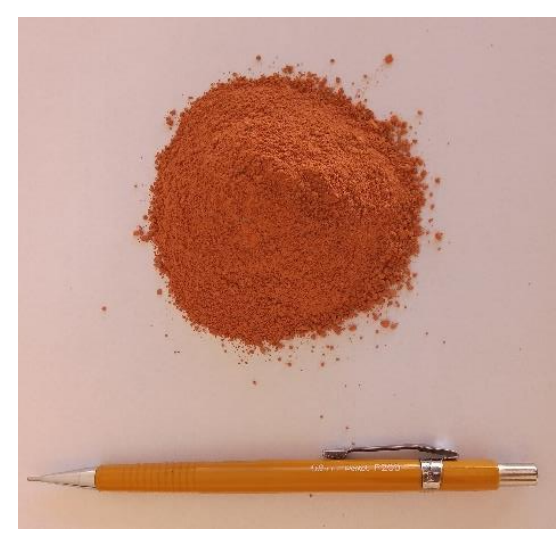

(a)

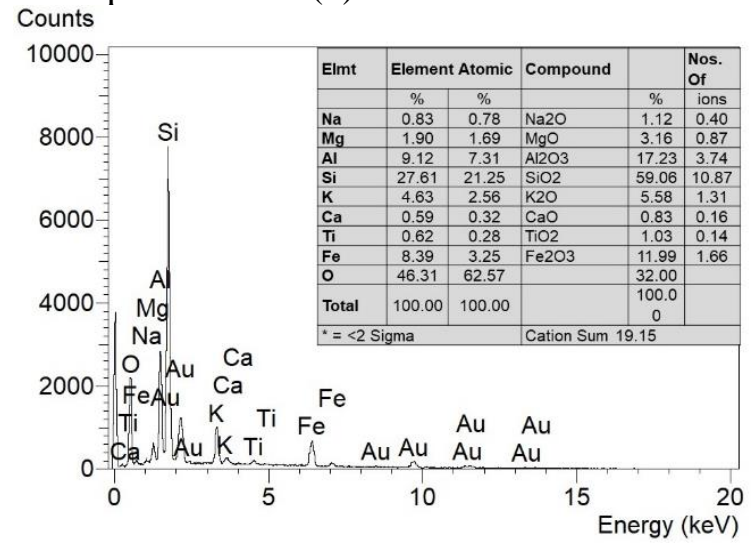

(b)

Fonte: Elaboração dos autores (2022).

Figura 4 - Resíduo de cerâmica branca, isoladores elétricos de porcelana (a) moídos em granulometria similar ao cimento Portland, e seu respectivo EDS (b).

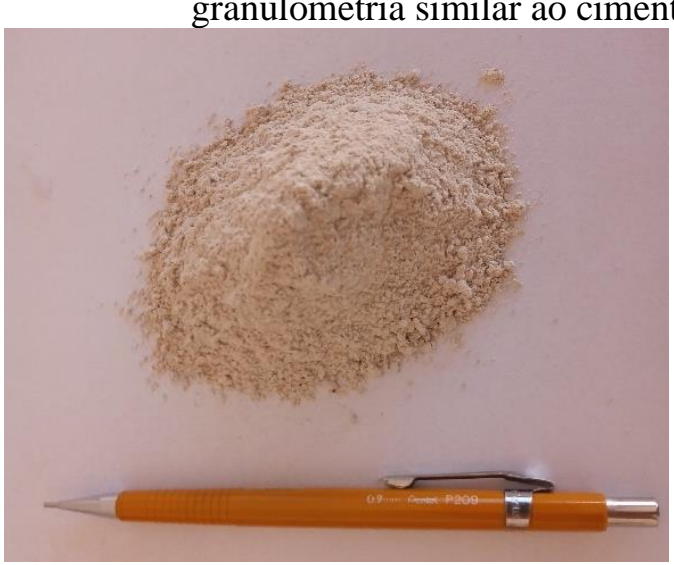

(a)

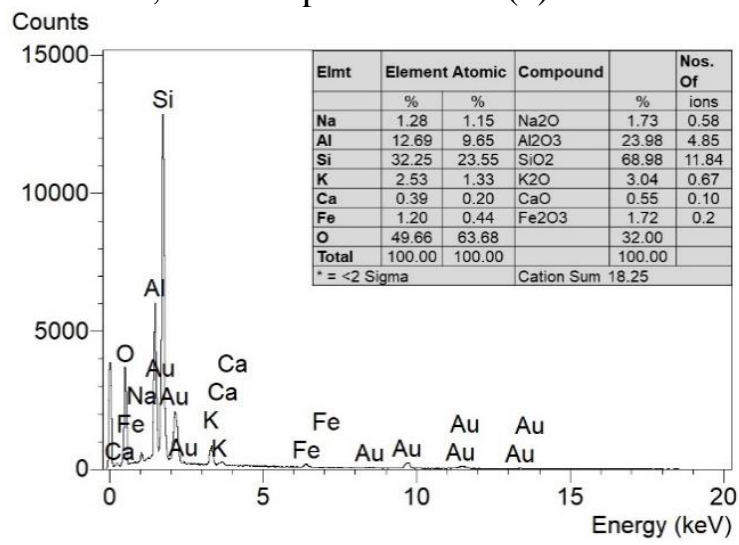

(b)

Fonte: Elaboração dos autores (2022). 
Observa-se através da análise das informações fornecidas pelo ensaio de EDS a similaridade entre seus materiais constituintes e aqueles constituintes do cimento Portland do tipo CPV-ARI, Figura 5 (a), e da sílica ativa, Figura 5 (b), utilizados nesta pesquisa.

Figura 5 - EDS Cimento Portland CPV-ARI (a), Sílica ativa (b).

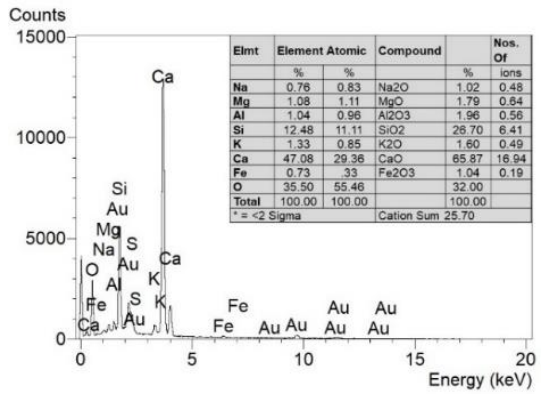

(a)

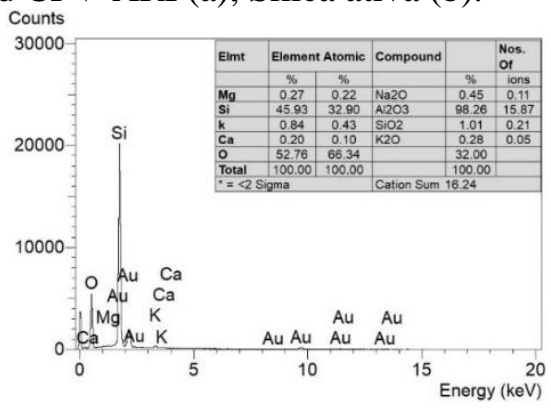

(b)

Fonte: Elaboração dos autores (2022).

Os isoladores elétricos de porcelana utilizados neste trabalho são aqueles referentes ao controle de qualidade fabril da indústria cerâmica, portanto, não contém materiais metálicos tão pouco o agente cimentante à base de enxofre, que é utilizado na fixação das hastes metálicas no corpo cerâmico dos isoladores. Para os isoladores provenientes da substituição de peças em serviço recomenda-se a retirada deste material metálico e do agente cimentante fixador, utilizando nestas condições apenas o corpo de porcelana.

A sílica ativa e os fílers cerâmicos possuem grande quantidade do composto silício ( $\mathrm{Si}$ ) que combinado ao oxigênio resulta no dióxido de silício, sílica $\left(\mathrm{SiO}_{2}\right)$ que é de extrema importância para hidratação do cimento e consequente aumento de resistência, quando em conjunto com o $\mathrm{CaO}$ (óxido de cálcio), presente no cimento, na formação do composto C-S-H.

A partir destes dados e de acordo com o traço de argamassa apresentado na NBR 7215 (1996), denominado traço referência, foi possível determinar o teor máximo de utilização do cimento Portland, fixado em $70 \%$, e os $30 \%$ de material aglomerante distribuído com $10 \%$ de sílica ativa e $20 \%$ de fíler cerâmico, ambos teores substituídos em massa.

A utilização do fíler cerâmico, 20\%, foi dividida em três traços, um contendo $20 \%$ de fíler cerâmico de telhas cerâmicas, outro com $20 \%$ de fíler de isoladores elétricos de porcelana e para o terceiro traço com fíler, foram combinados o teor de substituição de $10 \%$ por fíler de telhas cerâmicas e o $10 \%$ de fíler de isoladores de porcelana. 
A relação água-cimento foi fixada em 0:55 para todos os traços. A Tabela 2 ilustra as quantidades de materiais necessárias e recomendadas, pela NBR 7215 (1996), para moldar quatro corpos-de-prova de argamassa de $10 \mathrm{~cm}$ de altura e $5 \mathrm{~cm}$ de diâmetro. Todo o processo de moldagem foi realizado em atendimento a NBR 7215 (1996). Já o processo de cura foi do tipo submersa, isto é, os corpos-de-prova, após a desmoldagem, foram mantidos submersos em água até 24 horas antes de sua ruptura.

Tabela 2 - Quantidade de materiais em gramas para os traços de argamassa.

\begin{tabular}{lcccccc}
\hline Traço & $\begin{array}{c}\text { Cimento } \\
\text { Portland }\end{array}$ & $\begin{array}{c}\text { Sílica } \\
\text { Ativa }\end{array}$ & $\begin{array}{c}\text { Fíler } \\
\text { cerâmica }\end{array}$ & $\begin{array}{c}\text { Fíler de } \\
\text { porcelana }\end{array}$ & $\begin{array}{c}\text { Agregado } \\
\text { miúdo }\end{array}$ & Água \\
\hline Referência (AR) & 624,00 & - & - & - & $1.872,00$ & 343,20 \\
\hline Fíler Cerâmica (AFC) & 436,80 & 62,40 & 124,80 & - & $1.872,00$ & 343,20 \\
\hline Fíler Porcelana (AFP) & 436,80 & 62,40 & - & 127,80 & $1.872,00$ & 343,20 \\
\hline Mix Fíler (AMF) & 436,80 & 62,40 & 62,40 & 62,40 & $1.872,00$ & 343,20 \\
\hline
\end{tabular}

Fonte: Elaboração dos autores (2022).

Definido estes traços foi realizado o ensaio de caracterização das misturas de sílica e fíler comparando-as a referência (100\% de cimento), isto é, foram ensaiados os teores combinados de sílica ativa (10\%) e fíler de cerâmica (20\%); sílica ativa (10\%) e fíler de porcelana (20\%); e a combinação de $10 \%$ em teor do fíler de cerâmica e de $10 \%$ de fíler de porcelana com $10 \%$ de sílica ativa. Para ambas as misturas o teor em massa do cimento foi de $70 \%$.

Estes ensaios de caracterização foram em relação massa específica, NBR 16605 (2017), finura por meio da peneira $75 \mu \mathrm{m}$, NBR 11579 (2012) e determinação da finura pelo método de permeabilidade ao ar (Blaine) NBR 16372 (2015). Todos estes resultados são apresentados na Tabela 3, onde tem-se uma similaridade entre os resultados, apenas o teor de material passante na peneira $75 \mu \mathrm{m}$ foi maior para as misturas, mas isso já era esperado pois tanto a sílica ativa como os tipos de fíler possuem um grau de moagem superior ao cimento Portland.

Tabela 3 - Quantidade de materiais em gramas para os traços de argamassa.

\begin{tabular}{lccc}
\hline \multirow{2}{*}{ Material } & \multicolumn{3}{c}{ Caracterização } \\
\cline { 2 - 4 } & $\begin{array}{c}\text { Finura Blaine } \\
\left(\mathbf{c m}^{\mathbf{2} / \mathbf{k g})}\right.\end{array}$ & $\begin{array}{c}\text { Massa Específica } \\
\left(\mathbf{g} / \mathbf{c m}^{\mathbf{3}}\right)\end{array}$ & $\begin{array}{c}\text { Finura Peneira } \\
\mathbf{7 5} \boldsymbol{\mu \mathbf { m }} \mathbf{( \% )}\end{array}$ \\
\hline Cimento Portland CPV - ARI & 4.306 & 3,11 & 0,4 \\
\hline Sílica e Fíler Porcelana & 4.488 & 2,84 & 16,8 \\
\hline Sílica e Fíler Cerâmico & 4.061 & 3,01 & 22,4 \\
\hline Mix Fíler & 4.213 & 2,93 & 19,2 \\
\hline
\end{tabular}

Fonte: Elaboração dos autores (2022). 


\section{RESULTADOS E DISCUSSÃO}

Verificada a potencialidade de uso dos resíduos das indústrias cerâmicas através de alguns parâmetros de caracterização física e química, foram moldados traços de argamassa com matriz cimentícia e ensaiados à resistência à compressão simples nas idades de 28, 180 e 365 dias, conforme a NBR 7215 (1996). A Tabela 4 e a Figura 6 apresentam os valores médios e a evolução destes resultados.

Tabela 4 - Quantidade de materiais em gramas para os traços de argamassa.

\begin{tabular}{lccccc}
\hline & \multicolumn{5}{c}{ Evolução Resistência à Compressão Simples (MPa) } \\
\hline Traços & $\mathbf{2 8}$ dias & $\mathbf{1 8 0}$ dias & Evolução (\%) & $\mathbf{3 6 5}$ dias & Evolução (\%) \\
\hline Referência (AR) & 33,6 & 44,6 & 32,7 & 44,9 & 33,6 \\
\hline Fíler Cerâmica (AFC) & 31,0 & 37,7 & 21,6 & 38,5 & 24,2 \\
\hline Fíler Porcelana (AFP) & 37,3 & 47,4 & 27,1 & 50,1 & 34,3 \\
\hline Mix Fíler (AMF) & 33,4 & 43,6 & 30,5 & 47,5 & 42,2 \\
\hline
\end{tabular}

Fonte: Elaboração dos autores (2022).

Figura 6 - Evolução resistência à compressão simples.

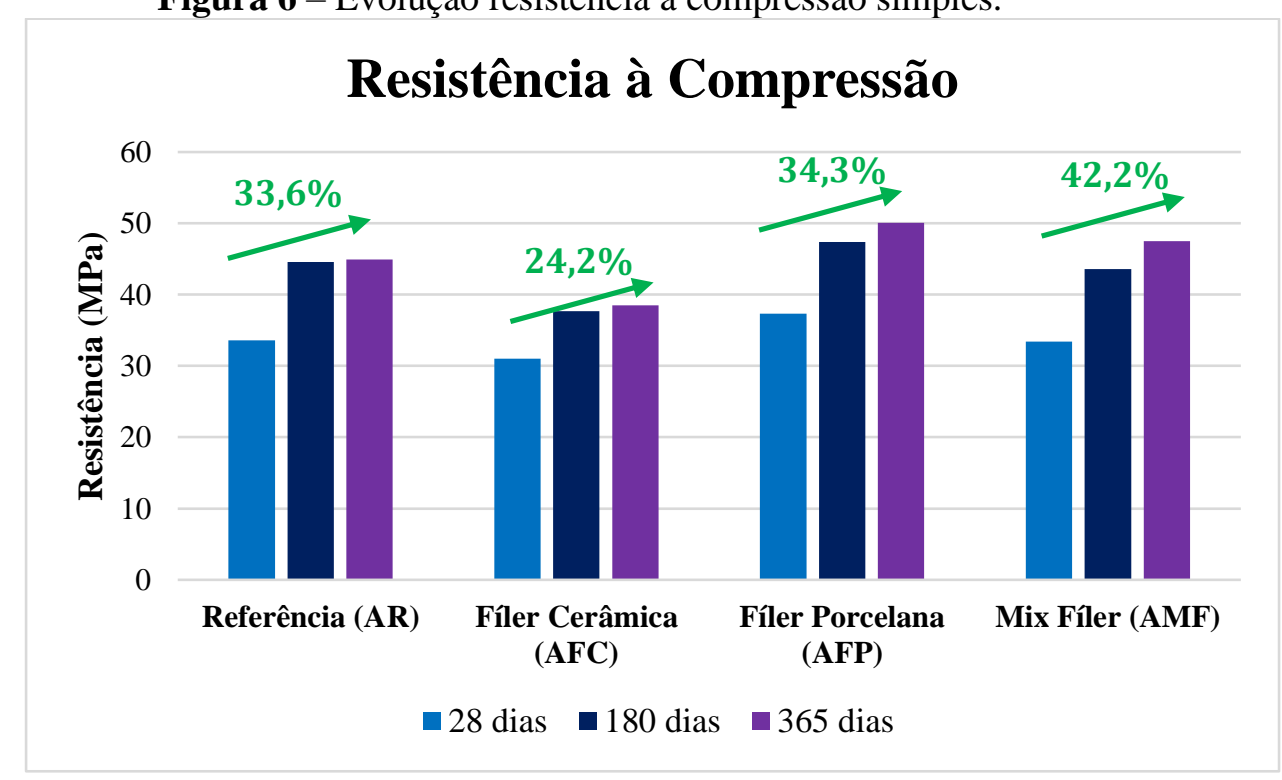

Fonte: Elaboração dos autores (2022).

Analisando os traços de argamassa verificou-se que o traço com fíler de porcelana (AFP) apresentou a maior resistência em todas as idades de ensaio e com 34,3\% na comparação da evolução da resistência. O traço com mix de fíler (AMF) apresentou a maior evolução, de 42,2\% na resistência. A argamassa referência (AR) apresentou evolução, 33,6\%, similar ao traço de AFP, entretanto, seus valores de carga de ruptura foram inferiores aos obtidos pelo traço com fíler de porcelana. As menores resistência e evolução foram medidas no traço com fíler de cerâmica (AFC), onde este tipo de resíduo cerâmico tem baixo índice de atividade pozolânica. 
Na comparação entre as idades de 180 e 365 os traços AR e AFC apresentaram pouca evolução nas cargas de ruptura ao passo que nas argamassas AFP e AMF as cargas de ruptura continuaram evoluindo, o que pode ser atribuído a um efeito tardio do fíler de porcelana.

A composição química dos fílers cerâmicos, com elevado teor de sílica ( $\mathrm{SiO} 2)$, contribui para o desenvolvimento das atividades pozolânicas que resultaram em elevadas resistências à compressão simples, tanto nos concretos como nas argamassas.

Portanto, as matrizes cimentícias propostas, com utilização de resíduos cerâmicos do Polo Cerâmico de Itu, cerâmica vermelha de telhas, e do Polo de Socorro, cerâmica branca de isoladores elétricos de porcelana, contendo $70 \%$ de cimento Portland, $10 \%$ de sílica e $20 \%$ de fíler cerâmico, podem ser utilizadas em concretos e argamassas, pois obtiveram resistências à compressão simples similares aos traços referências. Recomenda-se o estudo em idades mais avançadas e com a realização de outros ensaios mecânicos e de durabilidade, além da investigação da zona de transição agregado-pasta para verificação da formação dos produtos de hidratação destas matrizes cimentícias.

\section{CONCLUSÃO}

Os resíduos cerâmicos constituem motivo de preocupação pelos impactos ambientais que geram quando não são dispostos em locais apropriados, o que justifica o estudo e o desenvolvimento de metodologias para seu reaproveitamento.

Por ser um produto que tem a argila como principal matéria-prima é necessário que a sua produção esteja próxima ao local de extração para viabilizar o processo do ponto de vista econômico. Nestas condições é recorrente a criação de polos cerâmicos, o que desencadeia questões de ordenamento territorial, pois tem-se a extração de argila e a concentração de cerâmicas em um mesmo território. A região de Campinas, no interior de São Paulo possui em seu entorno quatro dos principais polos cerâmicos do estado.

Os polos de Rio Claro e de Mogi Mirim concentram a produção de pisos e revestimentos cerâmicos, no polo de Itu tem-se os produtos de cerâmica vermelha como telhas, tijolos e blocos, ao passo que no polo de Socorro a predominância é da cerâmica branca, em especial a porcelana de mesa e decoração e os isoladores elétricos de porcelana.

Alia-se à concentração dos polos cerâmicos em um mesmo território, o potencial volume de descarte que o controle de qualidade das indústrias determina. Mesmo havendo 
um bom reaproveitamento no processo fabril das próprias cerâmicas, há ainda um considerável volume de resíduo que pode ser reaproveitado em outros setores da construção civil, como proposto neste trabalho.

Com o avanço tecnológico, o controle de qualidade dos materiais cerâmicos tornou-se mais rigoroso, portanto, se a produção não se basear nas melhores técnicas de manufatura, maiores serão as quantidades de produtos reprovados por este controle de qualidade, acarretando significativos danos ambientais, dada a necessidade de extração de um maior volume de matéria-prima; o que acarreta, por sua vez, em perdas financeiras para as empresas do setor.

Na questão dos problemas ambientais, além da maior extração das argilas e outros constituintes, destacam-se também o armazenamento e o descarte em áreas irregulares destes resíduos, comprometendo em muitos casos toda a região em torno das cerâmicas. Soma-se a estes fatores o processamento mecânico - o beneficiamento da argila transformada em matéria-prima dos produtos cerâmicos. Na produção cerâmica, a argila é queimada a altas temperaturas, adquirindo resistência e durabilidade.

Portanto, o reaproveitamento destes resíduos cerâmicos é uma oportunidade para disciplinar o setor, respeitando as questões ambientais e territoriais, oferecendo benefícios econômicos aos agentes envolvidos, e - sobretudo - gerando um novo produto passível de utilização na construção civil.

O desenvolvimento de novas matrizes cimentícias é tema de pesquisa recente e necessário, visto que a indústria cimenteira é a maior fonte poluidora do mundo. A utilização de materiais com elevados teores de sílica $\left(\mathrm{SiO}_{2}\right)$ em sua composição há de ser prioritária pois este composto atua em conjunto com o óxido de cálcio $(\mathrm{CaO})$ na formação do C-S-H - produto de hidratação do cimento que lhe confere aumento da resistência.

Portanto os resíduos cerâmicos, telhas de cobertura, e os isoladores elétricos de porcelana - finamente moídos - são indicados para utilização como fíler pozolânico em matrizes cimentícias com baixo teor de cimento, pois possuem matérias-primas similares ao cimento Portland e sua produção envolve queima a altas temperaturas além do elevado teor de sílica. Recomenda-se a utilização destes fílers cerâmicos em conjunto com a sílica ativa, outro material com propriedade pozolânica para maiores ganhos de resistência.

A incorporação destes fílers em argamassas com baixo teor de cimento mostrou ser benéfica, pois os traços com fíler atingiram valores de resistência à compressão simples similares e até superiores ao traço de referência. 
A metodologia apresentada neste trabalho constitui-se em legado para próximas pesquisas visando o desenvolvimento de matrizes cimentícias com baixo teor de cimento Portland com a utilização de resíduos de isoladores elétricos de porcelana e telhas cerâmicas em concretos e argamassas.

Os benefícios advindos de tais estudos certamente se estenderão para toda a região dos polos de produção cerâmica, colaborando para com o aprimoramento do ordenamento territorial no que tange à logística da produção e à localização das minas de extração de argila, tendo em vista os locais de produção e consumo desses produtos, mas também - e talvez principalmente - promovendo o beneficiamento dos resíduos cerâmicos.

Contemplam estes benefícios não apenas o setor da construção civil, mas toda a cadeia produtiva dos polos cerâmicos e as comunidades localizadas no mesmo território, pois a utilização dos resíduos prejudiciais ao ambiente que antes eram descartados leva à diminuição da extração de materiais da natureza e o seu consequente beneficiamento industrial. Também a diminuição da poluição da indústria cimenteira acaba sendo benéfica para toda a sociedade.

\section{REFERÊNCIAS}

ARGOLlO FERRÃO, A. M.; CAMPOS, M. A.; PAULON, V. A. Reaproveitamento de resíduos de isoladores elétricos de porcelana como adição pozolânica em argamassas. In: Congresso Brasileiro de Cerâmica, 60, Águas de Lindóia. Anais[...] Águas de Lindóia, 2016.

ASSOCIAÇÃO BRASILEIRA DE CERÂMICA - ABCERAM. Cerâmica no Brasil Número do setor. Disponível em https://abceram.org.br/numeros-do-setor. Acesso 19 jul. 2021.

ASSOCIAÇÃO BRASILEIRA DE NORMAS TÉCNICAS - ABNT. NBR 7215 Cimento Portland - Determinação da resistência à compressão. Rio de Janeiro, 1996.

ASSOCIAÇÃO BRASILEIRA DE NORMAS TÉCNICAS - ABNT. NBR 11579 Cimento Portland - Determinação do índice de finura por meio da peneira $75 \mu \mathrm{m}$ (n⿳ 200). Rio de Janeiro, 2012.

ASSOCIAÇÃO BRASILEIRA DE NORMAS TÉCNICAS - ABNT. NBR 16372 Cimento Portland e outros materiais em pó - Determinação da finura pelo método de permeabilidade ao ar (método de Blaine). Rio de Janeiro, 2015.

ASSOCIAÇÃO BRASILEIRA DE NORMAS TÉCNICAS - ABNT. NBR 16605 Cimento Portland e outros materiais em pó - Determinação da massa específica. Rio de Janeiro, 2017. 
ASSOCIAÇÃO NACIONAL DOS FABRICANTES DE CERÂMICA PARA REVESTIMENTOS, LOUÇAS SANITÁRIAS E CONGÊNERES - ANFACER.

Números do setor cerâmico. Disponível em https://www.anfacer.org.br/numeros-dosetor. Acesso 19 jul. 2021.

ASSOCIAÇÃO PAULISTA DAS CERÂMICAS DE REVESTIMENTO - ASPACER. Estatísticas. Disponível em https://www.aspacer.com.br/estatisticas. Acesso 19 jul. 2021.

BERALDO, A.; SHIROMA, L.; FERREIRA, G. C. S. Compósito de cimento Portland com adição de resíduos de isoladores de porcelana e de Pinus. In: CLB-MCS 2014 "Congresso Luso-Brasileiro Materiais de Construção Sustentáveis, Guimarães Portugal. Anais[...] Guimarães - Portugal, 2014.

BUSTAMANTE, G. M.; BRESSIANI, J. C. A indústria cerâmica brasileira. Cerâmica Industrial, 5 (3), Maio/Junho, 2000, pp. 31-36.

CAMPOS, M. A.; PAULON, V. A.; DALFRÉ FILHO, J. G. (2013). Resíduos cerâmicos no município de Pedreira [SP]: equacionamento e soluções de reciclagem.

Labor \& Engenho, 7(1), pp. 74-83.

CAMPOS, M. A. Isoladores elétricos de porcelana na construção civil:

Propriedades, pesquisa e aplicação. Novas Edições Acadêmicas, Riga - Letônia, 2018.

CAMPOS, M. A.; ARGOLLO FERRÃO, A. M. (2018). Bloco de concreto com isoladores elétricos de porcelana e areia de fundição. In: CLB-MCS 2018 " $3^{\circ}$ Congresso Luso-Brasileiro Materiais de Construção Sustentáveis, 3, Coimbra-Portugal. Anais[...] Coimbra - Portugal, 2018.

CAMPOS, M. A.; PASSOS, L.; ARGOLLO FERRÃO, A. M. ; MORENO JUNIOR, A. L. (2018). Argamassa e concreto com baixo teor de cimento: utilização de fíler cerâmico e sílica ativa. In: Congresso Técnico Científico da Engenharia e da Agronomia - CONTECC-2018, Maceió, Anais[...] Maceió, 2018.

CARMO, J. B. M. DO; PORTELLA, K. F. Estudo comparativo do desempenho mecânico da sílica ativa e do metacaulim como adições químicas minerais em estruturas de concreto. Cerâmica, 54, 2008, pp. 309-318.

DAL MOLIN, D. C. C. (2005). Adições minerais para concreto estrutural. In: ISAIA, G. C. Concreto Ensino, Pesquisa e Realizações, IBRACON, São Paulo-SP, 2005.

DAL MOLIN, D. C. C. Contribuição ao estudo das propriedades mecânicas dos concretos de alta resistência com e sem adições de microssílica. Tese (Doutorado em Engenharia Civil), Universidade de São Paulo, São Paulo, 1994.

FARIAS FILHO, J.; ROLIM, J. S.; TOLEDO FILHO, R. D. Potencialidades da metacauolinita e do tijolo queimado moído como substitutos parciais do cimento Portland. Revista Brasileira de Engenharia Agrícola e Ambiental, v. 4, n. 3, 2000, pp. 437-444. 
FERREIRA, G. C. S.; BERALDO, A. L.; MESQUITA, V. H. L.; SHIROMA, L. Substituição parcial do cimento Portland por resíduo de porcelana de isoladores elétricos em matrizes cimentícias. In: Encontro Nacional Sobre Reaproveitamento de Resíduos na Construção Civil, São Leopoldo. Anais[...] São Leopoldo, 2013.

INSTITUTO DE PESQUISAS DO ESTADO DE SÃO PAULO S/A - IPT. (2018). Relatório Técnico No 153900-205: Estudo Estratégico da Cadeia Produtiva da Indústria Cerâmica no Estado de São Paulo. Disponível em https://www.ipt.br/download.php?filename=1772-

Estudo_Estrategico_da_Cadeia_Produtiva_da_Industria_Ceramica_no_Estado_de_Sao_ Paulo.pdf. Acesso 20 jul. 2021.

LOPES, G. DE A.; BRITO, J. O.; MOURA, L. F. DE. Uso energético de resíduos madeireiros na produção de cerâmicas no estado de São Paulo. Ciência Florestal, Santa Maria, v. 26, n. 2, 2016, p. 679-686.

MATIAS, G.; FARIA, P.; TORRES, I.; TOMÁS, A.; FERREIRA, T.; DUARTE, T. (2012). Argamassas de cal aérea com resíduos de cerâmica. In: Congresso de Argamassas de Construção da APFAC, 4, Coimbra-Portugal. Anais[...] Coimbra Portugal, 2012. Disponível em https://run.unl.pt/handle/10362/9487. Acesso 23 jul. 2021.

MEDEIROS, M. H. F.; SOUZA, D. J.; HOPPE FILHO, J.; ADORNO, C. S.; QUARCIONI, V. A.; PEREIRA, E. Resíduo de cerâmica vermelha e fíler calcário em compósito de cimento Portland: efeito no ataque por sulfatos e na reação álcali-sílica. Revista Matéria, v.21, n.2, 2016, pp. $282-300$.

MEHTA, P. K.; MONTEIRO, P. J. M. Concreto: Microestrutura, Propriedades e Materiais. IBRACON, São Paulo-SP, 2008.

NEVILLE, A. M.; BROOKS, J. J. Tecnologia do Concreto. Bookman, Porto AlegreRS, 2013.

OLIVEIRA, L. A. P., GOMES, J. P. C., SANTOS, P. M. S. The potential pozzolanic activity of glass and red-clay ceramic waste as cement mortars componentes.

Construction and Building Materials, v. 31, 2012, pp. 197-203.

PASSOS, L. Desempenho do concreto leve com agregado cerâmico reciclado em substituição ao agregado natural na execução de elementos estruturais. Tese (Doutorado em Engenharia Civil), Universidade Estadual de Campinas, Campinas-SP, 2019.

PRADO, U.S.; BRESSIANI, J. C. Panorama da indústria cerâmica brasileira na última década. In: Congresso Brasileiro de Cerâmica, 56, Curitiba. Anais[...] Curitiba, 2012.

REBMANN, M. S. Durabilidade de concretos estruturais com baixo consumo de cimento Portland e alta resistência. Dissertação (Mestrado em Engenharia Civil), Escola de Engenharia de São Carlos da Universidade de São Paulo. São Carlos-SP, 2011. 
ROCHA, C. A. A. Estudo de concretos com adições minerais de resíduo de corte de rocha e de blocos cerâmicos moídos. Dissertação (Mestrado em Engenharia Civil), Universidade Estadual do Norte Fluminense Darcy Ribeiro, Campos dos GoytacazesRJ, 2008.

RODRIGUES, L. L. Caracterização de materiais descartados de redes de distribuição de eletricidade para fins de reciclagem. Dissertação (Mestrado em Ciências e Tecnologia dos Materiais), Universidade Estadual de São Paulo "Júlio de Mesquita Filho", Sorocaba-SP, 2010.

SÃO PAULO. Polos cerâmicos do estado de São Paulo. Disponível em http://dadosenergeticos.energia.sp.gov.br/Portalcev2/Intranet/mineracao/mapas/mapa_p olos_ceramicos.jpg. Acesso 19 jul. 2021.

SOARES, M. da S. Argamassa convencional e colante com uso de resíduo de isolador de porcelana. Dissertação (Mestrado em Engenharia Civil), Universidade Estadual de Campinas, Campinas-SP, 2016.

VIEIRA, F. de L. Estudo da viabilidade do resíduo proveniente das porcelanas de isoladores para utilização em concretos bombeáveis estruturais. Dissertação (Mestrado em Engenharia Civil), Universidade Federal de Goiás, Goiânia-GO, 2017. 